\title{
The effects of airline alliances: what do the aggregate data say?
}

\author{
Philippe Gagnepain • Pedro L. Marín
}

Received: 12 March 2007 / Accepted: 12 December 2009 / Published online: 30 April 2010 (C) The Author(s) 2010. This article is published with open access at Springerlink.com

\begin{abstract}
We consider an empirical model of worldwide airline alliances that we apply to a large set of companies for the period 1995-2000. Using observations at the network level, we estimate a cost, capacity, and demand system that accounts for cross-price elasticities. Our contribution consists in evaluating airlines' strategical interactions through the window of firms' network interconnections. We consider networks coincidences and potential connections with all their rivals. The results allow us to classify all company pairs as either complements or substitutes. We shed light on the fact that many airlines involved in the same alliance are potential substitutes.
\end{abstract}

Keywords Alliance $\cdot$ Airline $\cdot$ Cross-price elasticities

JEL Classification $\quad \mathrm{L} 11 \cdot \mathrm{L} 13 \cdot \mathrm{L} 41$

\section{Introduction}

Using aggregate data at the airline level, we analyze worldwide airline alliances. We suggest that airlines inside alliances cut prices by $5 \%$ on average. We also propose an empirical model that allows us to evaluate to which extent two airlines' networks are substitutes. We suggest that a significant number of airlines enrolled in the same

Both authors are members of the CEPR. We would like to thank Pedro Mira and two anonymous referees for very helpful comments. We are also grateful to Jordi Jaumandreu for very constructive discussions, as well as Quim Beltrán for superb research assistance. Finally, funding from the Fundación Ramón Areces and Ministerio de Educación y Ciencia (SEJ2004-00670 and SEJ2007-66268) is gratefully acknowledged.

P. Gagnepain $(\varangle) \cdot$ P. L. Marín

Departamento de Economía, Universidad Carlos III de Madrid, C/ Madrid 126,

28903 Getafe (Madrid), Spain

e-mail: philippe@eco.uc3m.es 
alliances offer services which can be considered as substitutes, and this could lead to anti-competitive practices. We also evaluate price cost margins for each alliance and shed light on whether these margins obey some Nash pricing behavior.

There is increasing evidence suggesting that strategic alliances between otherwise independent firms have become commonplace in a wide variety of industries. According to Oster (1994), a strategic alliance could be defined as an arrangement in which two or more firms combine resources outside the market in order to accomplish a particular task or set of tasks. In the airline industry, deregulation has triggered several waves of alliances between worldwide airlines. Alliances between airlines are mainly designed to achieve fleet rationalization, expansion and rationalization of network structure as well as greater exploitation of cost economies. In particular, international airlines have the opportunity to extend their networks to foreign countries by entering an alliance agreement with a foreign airline. By coordinating their services or production processes, alliance partners can offer greater convenience to consumers, including access to connecting services, greater efficiencies and procedural operations in ticketing, ground handling and baggage handling, expanded route networks and connecting options.

Airlines can engage as well in cooperative pricing, while enjoying antitrust immunity. Strategic alliances in the airline industry have attracted more antitrust attention than any others. ${ }^{1}$ Many types of alliances have been adopted by airlines, ranging from agreements that involve relatively little cooperation such as frequent flyer programs to agreements commonly known as code sharing practices that involve the sharing of costly assets such as planes, terminals, counters, crews and more (see Oum and Park 1997, for more details on the forms of alliances in the airline industry). Code sharing arrangements have been until very recently the most popular form of alliance adopted by airlines. In this case, two companies operating two connecting routes offer an interline trip that is ticketed as if the two components were served by one single airline.

Economic studies focusing on the effect of airline alliances on welfare have identified various counter powered effects. Oum et al. (1996), Brueckner and Whalen (2000), Brueckner (2001 and 2003), and Whalen (2007) among others have focused on the competitive effects of international alliances. Bamberger et al. (2004) among others have investigated domestic alliances. These authors suggest that, if the corresponding networks of the alliance members offer the possibility of connecting many routes, they can be regarded as complements. In this case, firms cooperate on routes that were not individually served before, but are created by connecting networks. Accordingly, after the alliance, both prices and costs will fall and both buyers and sellers will be better off. In contrast, if the corresponding networks of alliance members used to overlap for a large number of routes, they can be regarded as substitutes (parallel alliances). In this case, the firms share planes on routes that they both used to served individually. This results in softer competition, and therefore, higher prices.

\footnotetext{
1 The European Commission Article 81 and 82 Treaty states that the Commission can exempt an alliance if it considers that the economic efficiencies and overall benefits of the transaction outweigh the anti-competitive effects.
} 
In this paper, we empirically analyze whether the network of individual alliance members is a substitute or a complement for the other alliance member's network. To do so, we estimate a cost, capacity, and demand system for airline companies, accounting for cross-price elasticities. Estimating demand entails proposing a original procedure in the specific context of the airline industry that allows us to reduce the number of cross price elasticity parameters to be estimated. In particular, we account for connecting and overlapping route between airlines' networks. We use annual aggregate data on firms' balance sheets, capacity and demand levels for all the international alliances that were operating between 1995 and 2000.

We also test for the effects of alliances on airlines' aggregate prices and costs. We confirm that being a member of an alliance entails cutting prices significantly with respect to airlines from outside alliances. However, we do not find any significant effect of the alliances on airlines' operating costs. Finally, we retrieve cost and demand parameters, construct marginal costs, and derive price-cost margins for each airline and alliance. We want to test whether some general pricing behavior can be observed at the airline level, i.e., we test whether pricing policies by airlines correspond to Nash pricing. Our results suggest that companies outside the alliances suffer from lower price-costs margins than those within alliances, even if, on average, they set higher prices.

The rest of the paper is organized as follows: The next section presents a discussion of the data we use and the associated methodology. Section 3 proposes to construct airlines' network substitution indexes. Section 4 presents the basic capacity, demand and cost ingredients which are inherent to our airline model. Section 5 focuses on the empirical implementation of the model. In particular, functional forms and the estimation procedure are presented. We develop in this section the procedure we use in order to model the price demand interactions between the different companies' networks of our dataset. Section 6 discusses our estimation procedure. In particular, we present the instruments we use to proxy airlines' fares in the demand equation. Section 7 is dedicated to the description of the dataset and the construction of the variables. Section 8 presents the estimation results. Section 9 proposes an evaluation of competitive forces in the industry. Finally, Sect. 10 concludes.

\section{Discussing the data and the model}

In what follows we specify a model of airlines' behavior that entails estimating the international demand faced by each airline as well as its technology. The ideal modelling approach consists in working at the airline-route level. This approach has been followed by Borenstein (1989), Oum et al. (1996), Brueckner and Whalen (2000), Brueckner (2001, 2003), or Whalen (2007), where a specific market is an origin destination pair. Given that airlines take different price and capacity decisions on each market they operate, working at the airline-route level allows the researcher to observe and account for each market characteristics such as the number and identity of the competitors, the length of the route, or the prices of each product available.

In this paper, we are interested in shedding light on alliance effects on airlines' behavior at a more aggregate level, i.e., at the airline level. Our motivation is twofold: 
First, the researcher focusing on non-U.S. airlines is usually constrained by the quality of the data available, which makes any work at the airline-route level unfeasible. ${ }^{2}$ Second, we aim at advocating the idea that airlines may take corporate and strategic decisions at the entire network level. An airline enters an alliance in order to expend its network overseas to destinations points that it could not reach otherwise, because of the high fixed costs induced, or because most countries do not permit cabotage by foreign companies. The decision of an airline to join an alliance and eventually find appropriate solutions to reorganize its productive structure affects its operating costs and the demand it faces at the network level. Airlines serve a large number of interconnected routes that form a network. Sometimes consumers buy a company's service in one single route (what is known as a direct flight) but very often they buy sets of (normally two or three) interconnected routes (indirect flights through one or two hubs). Additionally, when buying a ticket in an individual route, frequent consumers take into account the company's network size and characteristics, since this affects the flexibility to make further interconnections if needed, exchange tickets, take alternative routes and even enjoy frequent flyer prizes and discounts. Scope economies among routes and network effects (almost) impose a common policy to all the routes served by a given airline. ${ }^{3}$

In other words, we aim at proposing a different approach based on aggregate data which attempts to derive lessons at the airlines' network level rather than the route level. We propose two main contributions: First, we test for the impact of the formation of alliances on airlines annual prices and costs. We suggest that price reductions due to alliances are strong enough so that they can be identified through annual prices. We find no empirical evidence however of a direct effect of alliances on airlines' operating costs. Second, we propose an original demand framework that accounts for the intensity of competition in each airline's main hub. In particular, we account for the proportions of overlapping and connecting route kilometers between two airlines' main hub. We identify a substitution index cut-off above which two airlines' networks can be considered as substitutes.

The dataset has been constructed for the period 1995-2000 from raw data included in Digest of Statistics published by International Civil Aviation Organization (ICAO), World Air Transport Statistics published by International Air Transport Association (IATA), and Economic Outlook published by the Economics and Statistics Department of the Organization for Economic Cooperation and Development (OECD) as well as airlines annual reports. The companies under study are worldwide airlines with special

\footnotetext{
2 Data at the airline-route level are provided by the U.S. Department of Transportation. The database allows observing only interline trips where at least one route segment is flown on a U.S. airline. This implies for instance that it contains information on the United-Lufthansa or United-SAS pairs, but it does not on the routes jointly operated by Lufthansa and SAS. Data at the airline-route level for airlines outside the U.S. are in general very limited. For instance, the world air transport statistics published by the International Civil Aviation Organization (ICAO) and the Air Transport Association (IATA) do not contain observations on ticket prices at the route level.

3 This type of aggregate approach has been mostly used by authors measuring the effects of the European airline deregulation on airlines' costs reductions. This is the case for instance in Good et al. (1993), Neven and Röller (1996), Neven et al. (2006), Röller and Sickles (2000), Marín (1998), and Gagnepain and Marin (2006).
} 
Table 1 List of airlines included in the dataset

\begin{tabular}{|c|c|c|c|}
\hline Airline & Seats-kil. & Airline & Seats-kil. \\
\hline United Airlines & $272,380,784$ & Aeromexico & $16,770,044$ \\
\hline American Airlines & $250,920,342$ & Mexicana & $15,942,627$ \\
\hline Delta Airlines & $224,202,461$ & Finnair & $13,409,143$ \\
\hline Northwest & $153,461,676$ & Olympic & $13,157,697$ \\
\hline British Airways & $144,535,575$ & TAP & $12,837,742$ \\
\hline Japan Airlines & $112,853,559$ & Continental Micronesia & $9,200,909$ \\
\hline Continental Airlines & $108,316,288$ & Aer Lingus & $8,662,699$ \\
\hline Lufthansa & $103,576,477$ & Avianca & $7,275,610$ \\
\hline U.S. Air & $95,375,781$ & LOT & $6,707,159$ \\
\hline Air France & $94,723,686$ & Air Lanka & $6,628,365$ \\
\hline All Nippon Airways & $79,336,012$ & Air Europa & $4,987,922$ \\
\hline Qantas & $78,106,832$ & British Midland & $4,819,388$ \\
\hline KLM & $70,075,874$ & Spanair & $4,682,385$ \\
\hline TWA & $59,716,643$ & Braathens & $4,536,869$ \\
\hline Cathay Pacific & $56,506,464$ & Malev & $4,029,375$ \\
\hline Air Canada & $51,470,679$ & Cyprus Airways & $3,889,153$ \\
\hline Alitalia & $51,433,485$ & Air UK & $3,393,372$ \\
\hline Thai Airways & $47,788,381$ & Meridiana & $3,316,857$ \\
\hline Iberia & $43,128,693$ & Mea Air Liban & $3,233,606$ \\
\hline Swissair & $38,245,227$ & Gb Airways & $1,770,826$ \\
\hline America West & $37,929,149$ & Jersey European & $1,228,033$ \\
\hline Canadian Airlines & $35,288,169$ & Croatia Airlines & $1,020,691$ \\
\hline Varig & $35,199,155$ & Maersk Air & 727,783 \\
\hline SAS & $31,500,448$ & Lithuanian Airlines & 623,836 \\
\hline Virgin Atlantic & $26,642,135$ & Estonian Air & 408,050 \\
\hline Alaska Airlines & $25,589,388$ & Air Baltic & 268,564 \\
\hline Japan Air system & $22,201,996$ & Air Botswana & 109,663 \\
\hline Sabena & $20,714,658$ & & \\
\hline
\end{tabular}

Seats-kilometers supplied: average between 1995 and 2000

attention to the U.S. and the E.U. airlines, which usually constitute the main alliance partners. Some of the airlines belong to international alliances and some others operate as independent airlines. The dataset includes observations for a total of 55 airlines, as shown in Table 1. Table 2 presents a list of the different alliances members.

\section{A measure of network substitution}

We propose a methodology based on airlines' total networks. We define first in this section a measure of substitution between two airlines' networks. To illustrate our aim, we present an example in Fig. 1, where five airlines operate services on five networks. 
Table 2 Alliances

\begin{tabular}{|c|c|c|c|}
\hline & Alliance & Carrier & Date or entry \\
\hline & \multirow[t]{8}{*}{ OneWorld } & American Airlines & September 1998 \\
\hline & & British Airways & September 1998 \\
\hline & & Qantas & September 1998 \\
\hline & & Cathay & September 1998 \\
\hline & & Iberia & September 1999 \\
\hline & & Finnair & September 1999 \\
\hline & & Canadian & February 1999 \\
\hline & & Aer Lingus & June 2000 \\
\hline & \multirow[t]{4}{*}{ SkyTeam } & Delta & September 1999 \\
\hline & & Air France & September 1999 \\
\hline & & Alitalia & July 2001 \\
\hline & & Aeromexico & September 1999 \\
\hline & \multirow[t]{11}{*}{ Star Alliance } & United & May 1997 \\
\hline & & Lufthansa & May 1997 \\
\hline & & All Nippon & October 1999 \\
\hline & & Air Canada & May 1997 \\
\hline & & Thai & May 1997 \\
\hline & & Varig & October 1997 \\
\hline & & SAS & May 1997 \\
\hline & & Mexicana & July 1999 \\
\hline & & LOT & June 2003 \\
\hline & & British Midland & July 2000 \\
\hline & & Spanair & June 2003 \\
\hline & \multirow[t]{3}{*}{ Wings } & Northwest & 1989 \\
\hline & & KLM & 1989 \\
\hline & & Continental & 1989 \\
\hline & \multirow[t]{5}{*}{ Qualiflyer } & Swissair & March 1998 \\
\hline & & Sabena & March 1998 \\
\hline & & TAP & March 1998 \\
\hline \multirow{2}{*}{$\begin{array}{l}\text { "Date of entry" refers to the date } \\
\text { at which the carrier joins the } \\
\text { alliance }\end{array}$} & & LOT & January 2000 \\
\hline & & Air Europa & March 1999 \\
\hline
\end{tabular}

Some networks have no overlapping routes: This is the case for instance of network 1 and 2, which have a city (I) in common, but no overlapping routes. These two networks are said to be complements. As the number of overlapping route kilometers between two networks increases, so does the degree of substitutability between them. Networks 1 and 3 have one route in common; in particular, they share two cities, B and I. Networks 1 and 4 have two routes in common, given that they both operate at cities B, I, and H. Finally, networks 1 and 5 share all routes (cities A, B, I, and H), which makes them perfect substitutes. 
Fig. 1 Network overlapping

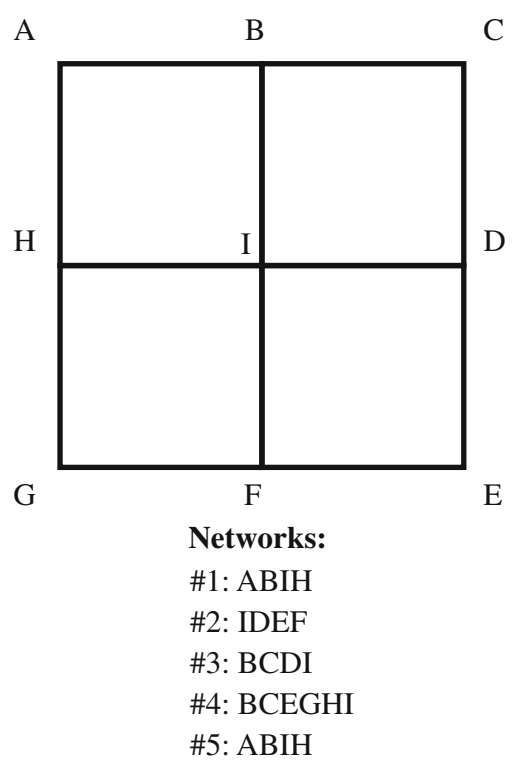

Hence, counting the number of route kilometers that two networks have in common allows us to derive a substitutability index between two networks. This in turn enables us to shed light on the degree of substitutability between two (average products of) airlines. Note however that, due to data restriction, we do not have detailed information on the activity of airlines on each route they operate. We are nevertheless able to observe airlines' operations in their respective hub. This is a potential drawback, since we do not observe the entire activity of an airline, but we are confident that the observation of airlines' activity through their hubs provides a fair instrument, as the hub is the center of gravity of airlines' operations. ${ }^{4}$

In Fig. 2, we illustrate how the measure of the airlines' network substitutability can be translated at the level of airlines' hubs. Consider two airlines 1 and 2 with respective hubs $\mathrm{H}_{1}$ and $\mathrm{H}_{2}$, from which they operate their services. In Fig $2 \mathrm{a}$, the number of overlapping routes between 1 and 2 is at its minimum level, i.e., airline 1 (2 resp.) does not propose any service in 2's (1's resp.) network besides the route that links $H_{1}$ and $H_{2}$. The two airlines' services are said to be complementary in this case, and it is very much alike the case of networks 1 and 2 in Fig. 1. In Fig 2b, Airline 1 (2 resp.) may decentralize a share of its operations to $H_{2}\left(H_{1}\right)$, increasing thus the degree of substitutability between 1 and 2's operations. This situation is similar to the networks pairs 1-3 and 1-4 above. Finally, in Fig 2c, both companies' hubs coincide, setting the degree of substitutability of both activities at the maximum level, as in the case of the network pair 1-5 above.

\footnotetext{
${ }^{4}$ If a carrier has several hubs (which is the case of many American carriers), the most important hub in terms of supply is accounted for. A detailed description of all companies' hubs as well as the level of supply operated from each of them is available upon request.
} 
Fig. 2 Hub overlapping. a Complementary networks, b intermediate degree of substitution, $\mathbf{c}$ high degree of substitution

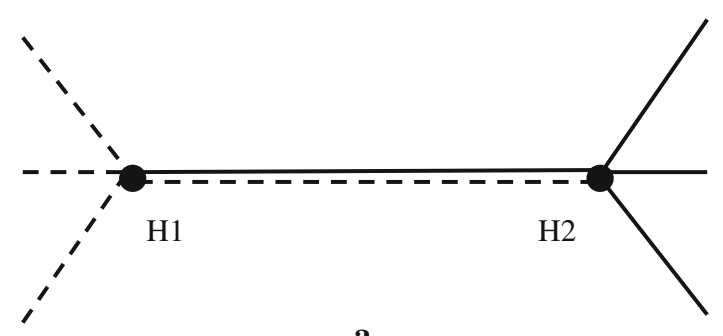

a

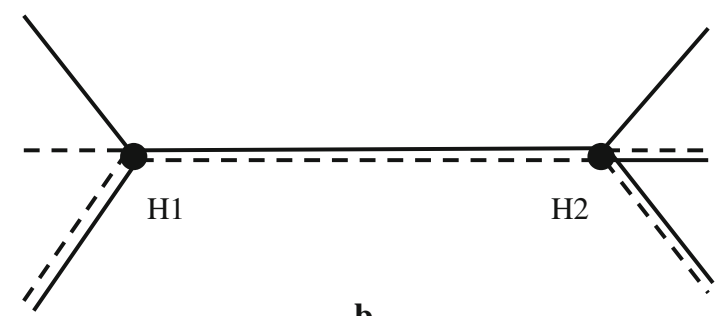

b

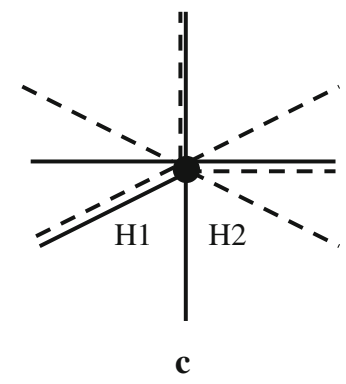

Hubs:

H1: Airline 1

H2: Airline 2

Routes:

- Airline 1

- - Airline 2

We construct our substitution index as follows: Consider two airlines $i$ and $j$. We suggest that the degree of substitutability (complementarity resp.) between the total operations of two airlines $i$ and $j$ increases (decreases resp.) with the share of route kilometers departing from $i$ and $j$ 's hubs and that $i$ and $j$ have in common. Define $O_{i j}$ as airline $i$ 's hub route kilometers also served by airline $j$. Likewise, define $O_{j i}$ as airline $j$ 's hub route kilometers also served by airline $i$. Moreover, denote as $T_{i}$ $\left(T_{j}\right)$ the total hub route kilometers for airline $i(j)$. Hence, the substitution index is defined as $O_{i-j}=\frac{\left(O_{i j}+O_{j i}\right)}{\left(T_{i}+T_{j}\right)}$. Note that a higher degree of substitution between $i$ and $j$ implies therefore that $O_{i-j}$ increases. 
We proceed in a similar fashion to construct a complementarity index between both airlines $i$ and $j$. Define as $C_{i j}$ the quantity of airline $i$ 's hub route kilometers not served by airline $j$, and $C_{j i}$ the quantity of airline $j$ 's hub route kilometers not served by airline $i$. Provided with these components it is possible to define $C_{i-j}=\frac{\left(C_{i j}+C_{j i}\right)}{\left(T_{i}+T_{j}\right)}$. Hence, a higher degree of complementarity between $i$ and $j$ implies therefore an increase of $C_{i-j}$. Moreover, $C_{i-j}=1-O_{i-j}$.

From our 55 airlines, we determine all the possible airline pairs. Out of the 1485 possibilities, 444 pairs are characterized by overlapping activities. We calculate the substitution index $O_{i-j}$ for each of them. Table 3 presents a list of the 87 airline pairs with the highest indexes. Some of these airline pairs present high substitution indexes because they operate from the same hub. This is the case for instance of All Nippon and Japan airlines (Hub: Tokyo), British Airways and Virgin Atlantic (Hub: London), Aeromexico and Mexicana (Hub: Mexico City), or Air Europa and Spanair (Hub: Madrid). Other pairs operate from distinct hubs located in the same domestic markets: Delta and TWA (Hubs: Atlanta and St Louis), and Air Canada and Canadian Airlines (Toronto and Calgary) for instance. Finally, one observes pairs of airlines with distinct hubs located in different countries. High substitution indexes in this case imply that these airlines operate a significant share of their total activity in their competitor's hub. Examples are Qantas and Thai (Hubs: Sydney and Bangkok), and British Airways and United (Hubs: London and Chicago).

Determining whether two airlines' operations can actually be considered as substitutes or complements requires the definition of a substitution index cut-off. This can be achieved through the estimation of a demand function for world airlines' operations, which constitutes the core of the analysis presented in this paper.

\section{Cost, capacity, and demand}

An airline offers a specific capacity determined by the total number of seats available in the airplanes, and the total mileage performed. Based on this supply and prices, consumers make optimizing travel decisions that consist of a particular number of trips. Hence, as already suggested by numerous authors, passenger-trips are not as much under the control of operators, and airlines are concerned by the capacity to produce a potential for trips (See Berechman 1993). In other words, costs and revenues are driven by two different variables that are closely related. It is thus crucial to disentangle the capacity supplied, $Q$, and the level of transport services requested by the customers, $q$.

Since the capacity supplied must at least meet the highest peaks of traffic, demand never saturates the network capacity on average. On the other hand, the capacity must be adjusted to the level of demand, so the former is endogenous to the latter. Here we do not present a complete model of optimal provision of transport services. Instead, we simply introduce a reduced form of a technical adjustment process between capacity and demand according to the relation that we specify as follows:

$$
Q_{i}=\Phi\left(q_{i}, \lambda\right)
$$


Table 3 Overlapping pairs

\begin{tabular}{|c|c|c|c|}
\hline Airline Pair & Index & Airline Pair & Index \\
\hline All Nippon-Japan Airlines & 0.5641 & Air France-Japan Airlines & 0.0907 \\
\hline Delta-TWA & 0.3860 & British Airways-United & 0.0859 \\
\hline Aeromexico-America West & 0.3484 & Lufthansa-Thai & 0.0854 \\
\hline SAS-Thai & 0.3358 & All Nippon-Sabena & 0.0834 \\
\hline Continental-TWA & 0.3118 & Japan Air System-Northwest & 0.0827 \\
\hline Air UK-Spanair & 0.3063 & United-Virgin & 0.0827 \\
\hline Continental-Delta & 0.2670 & Delta-Swissair & 0.0826 \\
\hline British Airways-Virgin & 0.2400 & British Airways-Delta & 0.0825 \\
\hline Aeromexico-Mexicana & 0.2383 & British Airways-Qantas & 0.0812 \\
\hline Continental Micro.-Japan Air Sys. & 0.1858 & Qantas-United & 0.0799 \\
\hline Air Europa-Spanair & 0.1829 & Alitalia-TWA & 0.0786 \\
\hline Japan Airlines-United & 0.1812 & Air France-Thai Airways & 0.0779 \\
\hline Olympic-TWA & 0.1795 & Continental-Mexicana & 0.0773 \\
\hline Mexicana-USAIR & 0.1539 & Continental-Virgin & 0.0757 \\
\hline Air UK-British Midland & 0.1536 & Delta-Virgin & 0.0752 \\
\hline Qantas-Thai & 0.1522 & Japan Airlines-Virgin & 0.0752 \\
\hline British Airways-Continental & 0.1518 & Air Europa-Iberia & 0.0735 \\
\hline American-Delta & 0.1501 & Japan Airlines-Lufthansa & 0.0734 \\
\hline Canadian Airlines-Cathay & 0.1413 & Delta-SAS & 0.0713 \\
\hline Japan Airlines-Northwest & 0.1374 & Air Canada-British Airways & 0.0698 \\
\hline Delta-Lufthansa & 0.1364 & Continental-Japan Air sys. & 0.0698 \\
\hline Air Canada-Canadian Airlines & 0.1355 & Air UK-KLM & 0.0693 \\
\hline Aeromexico-Iberia & 0.1314 & Air Europa-TWA & 0.0689 \\
\hline Olympic-Thai & 0.1307 & Swissair-Varig & 0.0686 \\
\hline All Nippon-Northwest & 0.1288 & British Airways-USAIR & 0.0680 \\
\hline Continental-SAS & 0.1263 & Delta-Sabena & 0.0669 \\
\hline Alitalia-Thai & 0.1261 & TAP-TWA & 0.0660 \\
\hline TAP-Varig & 0.1242 & Delta-United & 0.0656 \\
\hline Japan Airlines-Japan Air System & 0.1191 & Air France-TWA & 0.0647 \\
\hline American-Continental & 0.1178 & Air France-All Nippon Airw & 0.0641 \\
\hline Mexicana-United & 0.1173 & Continental-Lufthansa & 0.0640 \\
\hline American-British Airways & 0.1126 & Japan Air System-United & 0.0637 \\
\hline British Airways-Thai & 0.1116 & Air France-United & 0.0636 \\
\hline Lufthansa-United & 0.1101 & Cont. Micro.-Japan Airl. & 0.0631 \\
\hline American-United & 0.1066 & Iberia-Varig & 0.0630 \\
\hline Northwest-Qantas & 0.1049 & Japan Airlines-Thai & 0.0626 \\
\hline All Nippon-Qantas & 0.1046 & Cathay-Swissair & 0.0624 \\
\hline All Nippon-Virgin & 0.1028 & Air Canada-Iberia & 0.0620 \\
\hline Japan Airlines-Qantas & 0.0988 & Olympic-Qantas & 0.0619 \\
\hline Continental Micronesia-Northwest & 0.0987 & All Nippon-Cont. Micro. & 0.0618 \\
\hline
\end{tabular}


Table 3 continued

\begin{tabular}{llll}
\hline Airline Pair & Index & Airline Pair & Index \\
\hline All Nippon-United & 0.0980 & Delta-Varig & 0.0614 \\
Aeromexico-Continental & 0.0948 & American-Lufthansa & 0.0613 \\
Cathay-Qantas & 0.0930 & Iberia-TWA & 0.0613 \\
Air UK-Cathay & 0.0922 & $\ldots$ & \\
\hline
\end{tabular}

Only the first 87 over a total of 444 overlapping airline pairs are presented here

where $\lambda$ is a vector of parameters to be estimated. This equation just approximates how engineers adjust the network size and structure to the demand level on annual basis.

For the specification of the demand function, we follow the classical guidelines. Assume that from consumer $n$ 's indirect utility associated with the consumption of air transportation we can derive the individual long-run demand function:

$$
q_{i}\left(p_{i}, p_{j}, m_{i}, \alpha\right), \quad i=1, \ldots, N, \quad j \neq i,
$$

where $\alpha$ is a vector of parameters. Firm $i$ 's aggregate demand $q_{i}$ depends on its own price, $p_{i}$, competitors' prices $p_{j}$, as well as market exogenous characteristics $m_{i}$. A limited number of competitors meets in each route, with the combination of competitors changing from one route to another. Different competitors supply alternative products which differ in time schedule, number of stops, availability of interconnections with other flights, etc. In addition, at the two ends of each route start other routes that can be served by the same or a different set of airlines. Accordingly, the services offered by different airlines can be regarded either as imperfect substitutes or complements. By assuming the same pricing policy for all the routes served by one company, we are implicitly saying that $p_{j}$ represents the price asked by the different firms in the market, and this price accounts for the fact that the routes served by firms are complements or substitutes of those served by firm $i$. The price elasticity associated with this reduced-form demand corresponds to an estimate of the long-run elasticity, when capacity has been fully adjusted.

Moreover, airlines are endowed with a given technology. In order to provide a given amount of service, $Q_{i}$, an airline must buy variable inputs, namely, labor, $L_{i}$ and materials, $M_{i}$, which productivity depends on network exogenous characteristics, $z_{i}$. The production process and its underlying technology can be implemented through a long-run dual cost function. Denoting by $w_{L}$ and $w_{M}$ the price of labor and materials, the cost function is: ${ }^{5}$

$$
C_{i}=C\left(Q_{i}, \omega_{i}, z_{i}, t, A L L_{i}, \beta\right),
$$

\footnotetext{
5 We originally estimated a long run cost function where capital was regarded as a variable input. Accordingly, a measure for the price of capital was computed from the companies' accounting data and included in the cost function. This variable was not significant at any confidence level.
} 
where $t$ is a trend, and $\beta$ is a vector of parameters denoting technology. Note moreover that we test for the alliance effect on the company's costs. $A L L_{i}$ is a dummy variable that takes value 1 if the observed airline is part of an alliance, and 0 otherwise.

Our econometric model comprises three equations in a block-recursive structure, so that each equation can be estimated separately. The lower level provides the demand of transport that explains the demand (usage) of transport in terms of the transportation price, which is endogenous, and needs to be proxied. We will go back to this point below. The middle level is constituted by Eq. (1) that provides a relationship between demand and capacity (or supply). This equation just says that, at each period, one can identify the engineering function that has been used to set up the network structure in terms of size. The upper level is made of the cost function, which relates cost to capacity and to other elements like the inputs prices and the effect of alliances.

Note that we do not attempt to estimate firms' pricing strategy simultaneously with our aforementioned equations. The reason is that, since we work at the aggregate level, making any assumption on the "average" pricing conduct of airlines would not help to improve the quality of our estimates. We will provide further discussion on this aspect in Sect. 9.

\section{Empirical implementation}

The next step consists in proposing specific functional forms for our three equations. In particular, we explain how our demand function identifies the cross price effects between each pair of airlines observed in our database.

The demand equation corresponding to (2) is specified in linear form as follows

$$
q_{i}=\alpha_{1 i}+\alpha_{2 i} p_{i}+\sum_{j \neq i} \alpha_{i-j} p_{j}+\alpha_{m} m_{i}+u_{q i}, \quad i, j=1, \ldots, N
$$

where $u_{q i}$ is an error term. Notice that we allow the intercept $\alpha_{1 i}$ and the own-price effects $\alpha_{2 i}$ to vary across airlines. Moreover, we account for firms' cross-price specific effects $\alpha_{i-j}$. These characteristics imply a matrix of own and cross-price effects $\frac{\partial q_{i}}{\partial p_{j}}$ that can only be estimated imposing some constraints. Following the approach suggested by Jaumandreu and Lorences (2002), we assume that own-price and cross-price effects must follow some pattern.

First, we assume that the intercept and the total own-price effect of each airline are proportional to the size of its own network. Accordingly, we define $\alpha_{1 i}=\alpha_{0}+\alpha_{1} N E T_{i}$ and $\alpha_{2 i}=\alpha_{2} N E T_{i}$, i.e., we assume that the own rate effect of an airline depends on the size of its operations.

Second, the total cross-price effect of a rival $j$ depends on the extent to which $j$ 's network is a substitute or a complement to $i$ 's network. We therefore weight airlines' coincidences and potential connections with all their rivals. In particular, we define $\alpha_{i-j}=\alpha_{3} O_{i-j}+\alpha_{4} C_{i-j}$, where $\alpha_{3}$ and $\alpha_{4}$ are the common cross-price effects and $O_{i-j}$ and $C_{i-j}$ are the two overlapping and connecting indexes defined above. We expect $\alpha_{3}$ and $\alpha_{4}$ to be positive and negative respectively, i.e., a higher proportion of overlapping route kilometers $O_{i-j}$ (connecting route kilometers $C_{i-j}$ resp.) 
between two airlines $i$ and $j$ makes it more likely for these airlines to be substitutes (complements resp).

Defining $p_{i j}^{o}=O_{i-j} p_{j}$, and $p_{i j}^{c}=C_{i-j} p_{j}$, expression (4) can be transformed into an equation with only two cross-price parameters $\alpha_{3}$ and $\alpha_{4}$ to be estimated,

$$
\begin{aligned}
q_{i}= & \alpha_{0}+\alpha_{1} N E T_{i}+\alpha_{2} N E T_{i} p_{i}+\alpha_{3} \sum_{j \neq i} p_{i j}^{o}+\alpha_{4} \sum_{j \neq i} p_{i j}^{c} \\
& +\alpha_{m} m_{i}+u_{q i}, \quad i, j=1, \ldots, N
\end{aligned}
$$

Note that the whole matrix of own and cross-price effects can be recovered from this estimation for a given set of values of $N E T_{i}$, the $O_{i-j}$ and $C_{i-j}$ variables, and the $\alpha$ coefficients. Moreover, we define the cut-off value $O_{i-j}^{*}$ from which two airline $i$ and airline $j$ can be considered as substitutes: We need $\alpha_{i-j}>0$, i.e., $O_{i-j}>O_{i-j}^{*}=$ $-\frac{\alpha_{4}}{\alpha_{3}-\alpha_{4}}$. Likewise, two airlines are complements when $O_{i-j}<O_{i-j}^{*}=-\frac{\alpha_{4}}{\alpha_{3}-\alpha_{4}}$.

We turn now to the two other equations. We assume a Cobb-Douglas specification for the cost function in (3). This specification retains the main properties desirable for a cost function and provides a sufficiently precise description of the technology, while remaining tractable for our purpose. ${ }^{6}$ The cost function is then specified as

$$
C_{i}=\beta_{0} \omega_{L i}^{\beta_{1}} \omega_{M i}^{\beta_{2}} Q_{i}^{\beta_{3}} z_{i} \exp \left(\beta_{t} t+\beta_{A} A L L_{i}+u_{c i}\right)
$$

where $u_{c i}$ is an error term. Homogeneity of degree one in input prices is imposed, i.e., $\beta_{1}+\beta_{2}=1$. We assume that $z_{i}$ includes measures of airlines' network size, $N E T_{i}$, and average stage length, $A S L_{i},{ }^{7}$ and has the following shape:

$$
z_{i}=N E T_{i}^{\beta_{4}} A S L_{i}^{\beta_{5}}
$$

Note that the average stage length measures the length of the average route operated by an airline while the network size adds the length of all routes of the airline's network. With respect to the relationship between demand, $q_{i}$, and supply, $Q_{i}$, represented in (1), we assume the following functional form,

$$
Q_{i}=\lambda_{0} q_{i}^{\lambda_{1}} \exp \left(u_{Q i}\right)
$$

where $u_{Q i}$ is an error term.

\footnotetext{
6 See Marín (1998) for details on the same choice for the airline industry.

7 See Marín (1998) and Neven et al. (2006) for discussions on the introduction of these two variables in the cost function and for evidence on their effects on airlines' productivity. A measure of airport concentration was included in an alternative specification but it turned out to be highly correlated with the size of the network.
} 


\section{Estimation}

We estimate the sequential system of Eqs. (5), (6) and (8). Since prices $p_{i}$ in the demand equation (5) are endogenous, we need to find some instruments. We use as instruments for $p_{i}$ a trend $t$, the national private consumption in the airline's country of origin, $P R I V_{i}$, the size of population of the airline's country of origin, $P O P_{i}$, wages $\omega_{L i}$, a measure of competition $C O M P_{i}$, and a dummy indicating whether the airline belongs to an alliance or not, $A L L_{i}$ (All these variables are discussed in more details in the next section). Hence, we estimate the following additional equation:

$$
p_{i}=p\left(A L L_{i}, P R I V_{i}, P O P_{i}, \omega_{L i}, C O M P_{i}, t, \delta\right), \quad i=1, \ldots, N,
$$

where $\delta$ is a vector of parameters. Several comments are worth emphasizing: First, note that we test whether alliances have any impact on the global average price set by airlines using a simple dummy, in a similar fashion as in the cost equation. This procedure is similar to the one used by Brueckner and Whalen (2000) and Whalen (2007) with two differences: They measure the effects of codesharing and immunity agreements on prices while we rather focus on the effect of being a member of an alliance without specifying with precision the nature of the agreement. Moreover, as already mentioned, these authors work at the route (market) level while we focus on economic indicators aggregated at the network level. Note however that they consider that the codesharing and immunity agreements apply to all the products offered by airlines while in practice these agreements are effective in some specific markets only. In a sense, this "generalization" of airlines' cooperative behaviors generates an average effect on prices that is, to some extent, similar to our measures.

Second, entering an alliance is a decision of the airline and this has several consequences in our model: We should proxy the alliance variable $A_{i}$ since it is most probably endogenous. This is however a difficult task due to the fact that very few instruments are left in our database. We run several logit estimations on the choice of entering an alliance and obtained results where a trend, airlines' wages, and the (1995) airlines' network size significantly affect the probability to enter an alliance. Unfortunately, these instruments create important collinearity problems once prices are proxied in the demand equation. We therefore decided to discard the idea of proxying the decision to enter an alliance. Further comments on the logit estimation results are provided in Sect. 8.

Another consequence is that the overlapping and connection indexes $O_{i-j}$ and $C_{i-j}$ may themselves be decision variables of airlines. In order to avoid endogeneity problems at this level, we keep both $O_{i-j}$ and $C_{i-j}$ fixed over time, i.e., we use the initial 1995 indexes to proxy the degree of substitution and connection between airlines over the whole period of observation.

Finally, we compute several robustness checks to test the validity of our estimates of own and cross price elasticities. We show that the own elasticities do not vary much when prices are proxied or not. We also try other specifications of the demand equation. In particular, we replace $N E T_{i}$ in the expression of the constant and the own price parameter by the number of airline's flights departures $D E P_{i}$ and the number of routes $R O U T E S_{i}$. We suggest that these changes entail minor variation in the results. 


\section{Variables definition}

The variables have been constructed as follows. In the cost function, total costs $\left(C_{i}\right)$, production $\left(Q_{i}\right)$, wages $\left(\omega_{L i}\right)$, and average stage length $\left(A S L_{i}\right)$ correspond to total operating expenses, seat-kilometers available, flight crew salaries and maintenance and overhaul expenses over number of employees, and total aircraft kilometers over total aircraft departures $\left(D E P_{i}\right)$, respectively. With respect to total costs, companies report one single figure that corresponds to passengers, freight and mail activities. The distribution of operations among these three activities can vary significantly among companies. However, it is easy to obtain information on the total number of tons-Kilometers performed that correspond to passengers (including baggage), freight and mail, respectively. We multiply total costs reported by each company by the share of tons-kilometers performed corresponding to passengers in order to compute our cost variable $\left(C_{i}\right)$.

The variable $N E T_{i}$ is the total number of route kilometers an airline operates on all its different routes $\left(R O U T E S_{i}\right)$. Finally, the price of materials $\left(\omega_{M i}\right)$ has been constructed as the average fuel prices at the airline's home country and at the OECD, weighted by the company's domestic and international operations respectively.

On the demand side, demand $\left(q_{i}\right)$ corresponds to passenger-kilometers performed, and prices $\left(p_{i}\right)$ are measured as passenger revenues over passenger-kilometers performed. The home country exogenous characteristic $m_{i}$ is domestic private consumption $P R I V_{i}$. Finally, $t$ the time trend, is equal to one in 1995 and incremented by one each year.

We also construct a competition index $C O M P_{i}$ for each airline $i$, which accounts for the number and the intensities of coincidences of $i$ 's network with other airlines' networks. We have defined previously the substitution index $O_{i-j}=\frac{\left(O_{i j}+O_{j i}\right)}{\left(T_{i}+T_{j}\right)}$ as the share of route kilometers departing from two airlines $i$ and $j$ 's hubs and that $i$ and $j$ have in common. Summing $O_{i-j}$ over all airlines $j$ which coincide with $i$, we obtain a measure of the competition index, $C O M P_{i}=\sum_{j} O_{i-j}$ for airline $i$. Thus, airline $i$ faces a higher competitive pressure if $C O M P_{i}$ increases, i.e., if $i$ shares a higher quantity of route kilometers with its competitors.

Finally, we need to construct a variable to account for the alliance effects in the price and cost equations. Airlines cooperate with partners who are the members of the same alliance, i.e., ONE, SKY, STAR, WINGS, and QUAL. We construct a dummy $A L L_{i}$ which takes value one if the observed airline is a member of any of these alliances, and zero otherwise. Note that it is implicitly assumed that being a member of one of these alliances entails that an airline sets cooperative prices in all the markets where it is present.

Table 4 presents descriptive statistics.

\section{Demand elasticity and costs}

Tables 5, 6, 7, 8, 9, 10 and 11 provide the results for the econometric model. Prior to estimating the demand function (5), we need to obtain estimated prices $\hat{p}_{i}$ through the price equation (9). As a by-product, we test several price determinants, as presented in Table 5. We obtain price outcomes that are similar to the empirical results obtained 
Table 4 Descriptive statistics (annual data, 1995-2000, 55 airlines)

\begin{tabular}{|c|c|c|c|c|}
\hline Variable & Mean & SD & Min & Max \\
\hline Costs $\left(10^{3} \$\right)$ & $2,465,913$ & 172,663 & 11,820 & $14,901,114$ \\
\hline Wages (\$) & 14,969 & 510 & 773 & 59,094 \\
\hline Price Fuel (index) & 162.68 & 1.94 & 88.21 & 283.76 \\
\hline Price ticket (\$/Pass.kil) & 0.117 & 0.003 & 0.032 & 0.303 \\
\hline Production (Seats-kil) & $45,906,516$ & $3,450,119$ & 96,609 & $284,044,940$ \\
\hline Demand (Pass-kil) & $32,439,265$ & $2,469,556$ & 50,994 & $204,149,480$ \\
\hline Network size (kil) & 271,083 & 14,508 & 1,467 & $1,075,683$ \\
\hline Av. Stage Length (kil) & 1,385 & 57 & 277 & 8,978 \\
\hline \# Routes & 193.58 & 9.56 & 1.52 & 809.57 \\
\hline \# Departures & 177,587 & 12,315 & 4,029 & 968,893 \\
\hline Priv. Cons. (index) & 1443.70 & 117.44 & 1.29 & 6683.8 \\
\hline Competition (index) & 0.619 & 0.029 & 0.001 & 1.964 \\
\hline Alliance & 0.118 & & & \\
\hline OneWorld & 0.027 & & & \\
\hline Star Alliance & 0.060 & & & \\
\hline Wings & 0.061 & & & \\
\hline SkyTeam & 0.009 & & & \\
\hline Qualiflyer & 0.021 & & & \\
\hline
\end{tabular}

by Brueckner and Whalen (2000) and Whalen (2007), although these authors work at a more disaggregated level, i.e., on a market (route) basis. First, note that prices decrease at an annual rate of $4-7 \%$ as suggested by the trend. Second, prices are higher, on average, if the domestic private consumption inside the home country of the observed airline is more important. Third, the size of the population of the home country of the observed airline and the price are inversely related, which suggests that this variable is a potential proxy for the quantity of passengers-kilometers carried.

Note that the average wage paid to the employees of the airline is not a relevant determinant of the price, suggesting that a direct connection between airlines' prices and costs is potentially loose. Whether or not an airline is a member of an alliance has a significant impact. On average, prices are 5-6\% lower under alliances. This is an interesting result, given the highly aggregated nature of the data. Although airlines establish strategic price interactions on a market to market basis, prices reductions are important enough so that these reductions can be identified in annual average prices at the airline level. Interacting the alliance variable with our measure of competition yields the expected negative results, i.e., prices are lower for alliance members facing a higher competitive pressure.

As suggested previously, we also estimate the decision of airlines to enter an alliance. ${ }^{8}$ Replacing $A L L_{i}$ in the price equation by this estimated probability reduces

\footnotetext{
8 The estimated probability to enter an alliance is $\mathrm{Pr}=-30.62+6.91$ TREND $+1.59 N E T-$ $0.61 W A G E S$. Standard errors are in parenthesis. $(0.31)$
} 
Table 5 Prices

\begin{tabular}{|c|c|c|c|c|c|}
\hline Variable & I & II & III & IV & V \\
\hline CONST & $-4.70^{* * *}(0.26)$ & $-1.01(2.19)$ & $-2.65^{* * *}(0.07)$ & $-4.65^{* * *}(0.25)$ & $-4.69^{* * *}(0.29)$ \\
\hline TREND & $-0.07^{* * *}(0.01)$ & $-0.06^{* * *}(0.01)$ & $-0.04^{* * *}(0.01)$ & $-0.06^{* * *}(0.01)$ & $-0.06^{* * *}(0.01)$ \\
\hline PRIV & $0.41^{* * *}(0.05)$ & $0.41^{* * *}(0.04)$ & & $0.39^{* * *}(0.04)$ & $0.40^{* * *}(0.05)$ \\
\hline$P O P$ & & $-0.22^{*}(0.13)$ & & & \\
\hline WAGES & & & $0.04(0.03)$ & & \\
\hline$A L L$ & & & & $-0.05^{* *}(0.02)$ & $-0.06^{* * *}(0.02)$ \\
\hline$A L L \times C O M P$ & & & & & $-0.06^{*}(0.03)$ \\
\hline Error Dev. & $0.09^{* * *}(0.003)$ & $0.09^{* * *}(0.003)$ & $0.09^{* * *}(0.003)$ & $0.09^{* * *}(0.02)$ & $0.09^{* * *}(0.003)$ \\
\hline$R$ Squared & 0.96 & & & & \\
\hline Mean Log-likelihood & 1.92 & & & & \\
\hline \# of observations & 330 & 330 & 330 & 330 & 330 \\
\hline
\end{tabular}

Standard errors are in parenthesis

*** Significant at the $1 \%$ level; ${ }^{* *}$ significant at the $5 \%$ level; ${ }^{*}$ significant at the $10 \%$ level

significantly the magnitude of the alliance effect ( $-1 \%$ instead of $-5 \%)$, although the alliance outcome remains negative and highly significant. This suggests a potential endogeneity bias: Airlines entering alliances may enjoy lower costs than those not entering. In particular, the former may be more efficient and/or larger firms. Not accounting for this issue may lead to an overstatement of the alliance effects on prices.

From the different price specifications in Table 5, we derive measures $\hat{p}_{i}$ which are introduced in our demand equation. Tables 6,7 and 8 present the results for the demand equation. Table 6 shows the results of the demand equation (5). In Tables 7 and 8 , we produce alternative estimates obtained from the estimation of (5) where $N E T_{i}$ is replaced by the number of routes, ROUTES $S_{i}$, and the number of departures $D E P_{i}$, respectively. All the coefficients have the expected signs. As expected, demand increases significantly with the size of the network, the number of aircraft departures, or the number of routes operated. Likewise, private consumption growth affects positively demand. The own price parameter $\alpha_{2}$ is negative and significant, and do not vary much depending on whether the size of the network, the number of routes, or the number of departures enter the specification of the own price demand elasticity. Note moreover that, from Table 6, plugging into the demand function the real observed price $p_{i}$ (Column $\mathrm{A}$ ) or the estimated $\hat{p}_{i}$ (Columns I to $\mathrm{V}$ ) do not affect much $\alpha_{2}$. With respect to cross price estimates, it appears that $\alpha_{3}$ ( $\alpha_{4}$ resp.) is positive (negative resp.) and significant. This result suggests that a higher proportion of overlapping route kilometers between two airlines $i$ and $j$ makes it more likely for these airlines to be substitutes. Likewise, a higher proportion of connecting route kilometers between two airlines $i$ and $j$ makes it more likely for these airlines to be complements.

From the estimation of the own price parameter $\alpha_{2}$ obtained in Tables 6, 7 and 8, we evaluate the own price demand elasticity as $\theta_{i i}=\alpha_{2} N E T_{i} \times\left(\frac{p_{i}}{q_{i}}\right)$. We obtain 


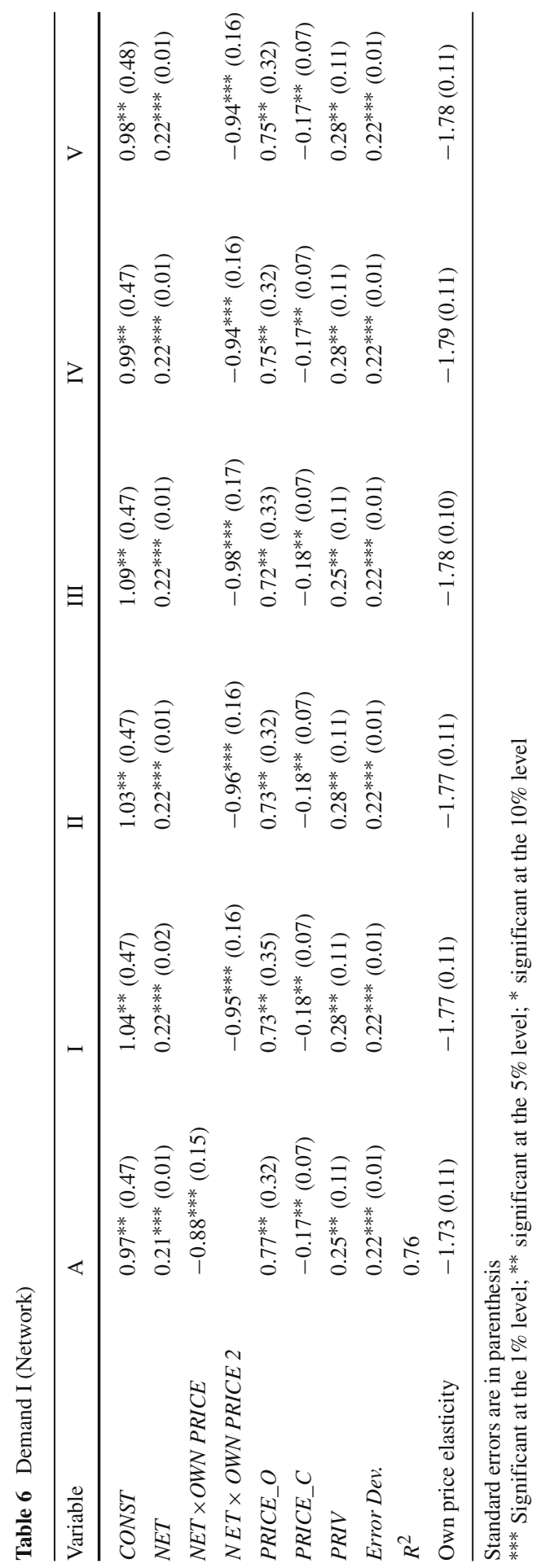


Table 7 Demand II (Departures)

\begin{tabular}{llllll}
\hline Variable & I & II & III & IV & V \\
\hline CONST & $1.06^{* * *}(0.34)$ & $1.05^{* * *}(0.34)$ & $1.06^{* * *}(0.33)$ & $1.02^{* * *}(0.34)$ & $1.00^{* * *}(0.34)$ \\
DEP & $0.29^{* * *}(0.01)$ & $0.29^{* * *}(0.01)$ & $0.29^{* * *}(0.01)$ & $0.29^{* * *}(0.01)$ & $0.29^{* * *}(0.01)$ \\
DEP $\times$ OWN PRICE & $-1.48^{* * *}(0.14)$ & $-1.49^{* * *}(0.14)$ & $-1.53^{* * *}(0.14)$ & $-1.48^{* * *}(0.14)$ & $-1.48^{* * *}(0.14)$ \\
PRICE_O & $2.02^{* * *}(0.19)$ & $2.02^{* * *}(0.19)$ & $2.01^{* * *}(0.19)$ & $2.03^{* * *}(0.19)$ & $2.03^{* * *}(0.19)$ \\
PRICE_C & $-0.17^{* * *}(0.05)$ & $-0.17^{* * *}(0.05)$ & $-0.17^{* * *}(0.05)$ & $-0.17^{* * *}(0.05)$ & $-0.16^{* * *}(0.05)$ \\
PRIV & $-0.02^{* * *}(0.005)$ & $-0.01^{* * *}(0.005)$ & $-0.02^{* * *}(0.005)$ & $-0.02^{* * *}(0.006)$ & $-0.02^{* * *}(0.005)$ \\
Error Dev. & $0.15^{* * *}(0.006)$ & $0.15^{* * *}(0.005)$ & $0.15^{* * *}(0.006)$ & $0.15^{* * *}(0.06)$ & $0.15^{* * *}(0.005)$ \\
$R^{2}$ & 0.88 & & & & \\
Own price elasticity & $-1.53(0.11)$ & $-1.53(0.11)$ & $-1.51(0.10)$ & $-1.53(0.11)$ & $-1.54(0.11)$ \\
\hline
\end{tabular}

Standard errors are in parenthesis

*** Significant at the $1 \%$ level; ${ }^{* *}$ significant at the $5 \%$ level; ${ }^{*}$ significant at the $10 \%$ level

Table 8 Demand III (Routes)

\begin{tabular}{llllll}
\hline Variable & I & II & III & IV & V \\
\hline CONST & $1.06^{* *}(0.47)$ & $1.05^{* *}(0.47)$ & $1.14^{* *}(0.47)$ & $1.02^{* *}(0.47)$ & $1.01^{* *}(0.47)$ \\
ROUTES & $0.26^{* * *}(0.02)$ & $0.26^{* * *}(0.02)$ & $0.27^{* * *}(0.02)$ & $0.26^{* * *}(0.02)$ & $0.26^{* * *}(0.02)$ \\
ROUTES $\times$ OWN PRICE & $-1.35^{* * *}(0.19)$ & $-1.35^{* * *}(0.19)$ & $-1.41^{* * *}(0.20)$ & $-1.33^{* * *}(0.19)$ & $-1.33^{* * *}(0.19)$ \\
PRICE_O & $1.39^{* * *}(0.30)$ & $1.39^{* * *}(0.30)$ & $1.37^{* * *}(0.30)$ & $1.41^{* * *}(0.30)$ & $1.41^{* * *}(0.30)$ \\
PRICE_C & $-0.19^{* * *}(0.07)$ & $-0.18^{* *}(0.07)$ & $-0.20^{* * *}(0.07)$ & $-0.18^{* *}(0.07)$ & $-0.18^{* *}(0.07)$ \\
PRIV & $0.07^{* * *}(0.006)$ & $0.07^{* * *}(0.006)$ & $0.07^{* * *}(0.006)$ & $0.07^{* * *}(0.006)$ & $0.07^{* * *}(0.006)$ \\
Error Dev. & $0.21^{* * *}(0.008)$ & $0.21^{* * *}(0.008)$ & $0.21^{* * *}(0.008)$ & $0.21^{* * *}(0.01)$ & $0.21^{* * *}(0.01)$ \\
$R^{2}$ & 0.77 & & & & \\
Own price elasticity & $-1.99(0.12)$ & $-1.98(0.12)$ & $-1.99(0.12)$ & $-1.99(0.12)$ & $-1.98(0.12)$ \\
\hline
\end{tabular}

Standard errors are in parenthesis

${ }^{* * *}$ Significant at the $1 \%$ level; ${ }^{* *}$ significant at the $5 \%$ level; ${ }^{*}$ significant at the $10 \%$ level

estimates between -1.51 and -1.99 for the average airline over the period considered. ${ }^{9}$ More interestingly, using the cross price demand parameters $\alpha_{3}$ and $\alpha_{4}$, we derive the substitution cut-off $O_{i-j}^{*}=-\frac{\alpha_{4}}{\alpha_{3}-\alpha_{4}}$ above which two airlines can be considered as substitutes. From the demand results $\widehat{\alpha_{3}}$ and $\widehat{\alpha_{4}}$ obtained in Table 6 (Tables 7 and 8 resp.), the cut-off $O_{i-j}^{*}$ is 0.180 (0.113 and 0.077 resp.). ${ }^{10}$ Hence, substitute airline pairs are those for which $O_{i-j}^{*} \geq 0.180$ (0.113 and 0.077 resp.) in Table 3, i.e., we identify 12 substitute airline pairs (31 and 57 resp.), which represents $2.7 \%$ (6.9 and $12.8 \%$ resp.) of the airline pairs characterized by overlapping activities.

\footnotetext{
9 A survey by Oum et al. (1992) on price elasticities of air transport demand suggests that empirical findings obtained during the 80 s usually lie between -4.51 and -0.4 .

10 We keep the worst case scenario from each table.
} 
Table 9 Pairs of substitute carriers

\begin{tabular}{|c|c|c|c|}
\hline Airline Pair & Index & Airline Pair & Index \\
\hline All Nippon-Japan Airlines & 0.5641 & American-Continental & 0.1178 \\
\hline Delta-TWA & 0.3860 & Mexicana-United & 0.1173 \\
\hline Aeromexico-America West & 0.3484 & American-British Airways & 0.1126 \\
\hline SAS-Thai & 0.3358 & British Airways-Thai & 0.1116 \\
\hline Continental-TWA & 0.3118 & Lufthansa-United & 0.1101 \\
\hline Air UK-Spanair & 0.3063 & American-United & 0.1066 \\
\hline$\underline{\text { Continental-Delta }}$ & 0.2670 & Northwest-Qantas & 0.1049 \\
\hline British Airways-Virgin & 0.2400 & All Nippon-Qantas & 0.1046 \\
\hline Aeromexico-Mexicana & 0.2383 & All Nippon-Virgin & 0.1028 \\
\hline Continental Micro.-Japan Air Sys. & 0.1858 & $\underline{\text { Japan Airlines-Qantas }}$ & 0.0988 \\
\hline Air Europa-Spanair & 0.1829 & Continental Micro-Northwest & 0.0987 \\
\hline Japan Airlines-United & 0.1812 & All Nippon-United & 0.0980 \\
\hline Olympic-TWA & 0.1795 & Aeromexico-Continental & 0.0948 \\
\hline Mexicana-USAIR & 0.1539 & Cathay-Qantas & 0.0930 \\
\hline Air UK-British Midland & 0.1536 & Air UK-Cathay & 0.0922 \\
\hline Qantas-Thai & 0.1522 & Air France-Japan Airlines & 0.0907 \\
\hline British Airways-Continental & 0.1518 & British Airways-United & 0.0859 \\
\hline American-Delta & 0.1501 & $\underline{\text { Lufthansa-Thai }}$ & 0.0854 \\
\hline Canadian Airlines-Cathay & 0.1413 & All Nippon-Sabena & 0.0834 \\
\hline Japan Airlines-Northwest & 0.1374 & Japan Air System-Northwest & 0.0827 \\
\hline Delta-Lufthansa & 0.1364 & United-Virgin & 0.0827 \\
\hline Air Canada-Canadian Airlines & 0.1355 & Delta-Swissair & 0.0826 \\
\hline Aeromexico-Iberia & 0.1314 & British Airways-Delta & 0.0825 \\
\hline Olympic-Thai & 0.1307 & British Airways-Qantas & 0.0812 \\
\hline All Nippon-Northwest & 0.1288 & Qantas-United & 0.0799 \\
\hline Continental-SAS & 0.1263 & Alitalia-TWA & 0.0786 \\
\hline Alitalia-Thai & 0.1261 & Air France-Thai Airways & 0.0779 \\
\hline TAP-Varig & 0.1242 & Continental-Mexicana & 0.0773 \\
\hline Japan Airlines-Japan Air System & 0.1191 & & \\
\hline
\end{tabular}

Table 10 Demand-capacity relationship

\begin{tabular}{ll}
\hline Variable & Parameter \\
\hline CONST & $1.58^{* * *}(0.28)$ \\
$q$ & $0.92^{* * *}(0.01)$ \\
Error Dev. & $0.05^{* * *}(0.002)$ \\
$R^{2}$ & 0.99
\end{tabular}

Standard errors are in parenthesis

*** Significant at the $1 \%$ level; ${ }^{* *}$ significant at the $5 \%$ level; ${ }^{*}$ significant at the $10 \%$ level 
Table 11 Cost function

\begin{tabular}{lll}
\hline Variable & $\mathrm{A}$ & $\mathrm{A} 2$ \\
\hline CONSTANT & $-4.95^{* * *}(0.24)$ & $-4.99^{* * *}(0.25)$ \\
WAGE & $0.24^{* * *}(0.02)$ & $0.24^{* * *}(0.02)$ \\
$Q$ & $0.93^{* * *}(0.02)$ & $0.93^{* * *}(0.02)$ \\
NET & $-0.07^{* *}(0.03)$ & $-0.07^{* *}(0.03)$ \\
$A S L$ & $-0.38^{* * *}(0.04)$ & $-0.38^{* * *}(0.04)$ \\
TREND & $-0.15^{* * *}(0.03)$ & $-0.15^{* * *}(0.03)$ \\
ALL & & $-0.03(0.06)$ \\
Error Dev. & $0.30^{* * *}(0.01)$ & $0.30^{* * *}(0.01)$ \\
$R^{2}$ & 0.97 & \\
\hline
\end{tabular}

Table 9 identifies the pairs of airlines whose services are substitutes. Airlines pairs which are members of the same alliances over 1995-2000 are underlined. Airline pairs which become members of the same alliance after our period of observation are underlined and in italic. Interestingly, a significant number of pairs of substitute airlines belongs to the same alliance, which may lead to softer competition and higher prices. Among the pairs with the highest substitution index are SAS and Thai, (Star Alliance from 1997), Continental and Delta (Skyteam from 2004), or Canadian Airlines and Cathay (OneWorld from 1999). Note also the presence of the pair American AirlinesBritish airways (OneWorld since 1998) which required antitrust immunity on transatlantic routes in 1997 and 2001 without success, or the pair Lufthansa-United which got granted antitrust immunity in 1997 under very specific restrictions on some particular routes such as Washington/Frankfurt and Chicago/Frankfurt. ${ }^{11}$ More recently, the European Commission opened two antitrust proceedings against these four airlines together with other members of Star Alliance (Air Canada and Continental) and OneWorld (Iberia) in relation to cooperation on transatlantic routes. ${ }^{12}$ The Commission is willing to assess whether cooperation among these airlines may lead to restrictions of competition on certain routes. These cases illustrate that a methodology based on network substitution such as the one presented in this paper may be a relevant tool for regulators when deciding whether or not two airlines should be allowed cooperative arrangements. We turn to the capacity and cost side of our results.

Table 10 presents the demand-capacity relationship. Again, the coefficients are significant and have the expected sign. Table 11 presents the estimates for the cost function. All the parameters are significant and have the expected sign. Costs increase with wages and production. The production process is characterized by increasing returns to scale since the production parameter $\beta_{3}$ is significantly lower than 1 . The coefficient of the time trend is negatively signed, suggesting the presence of technological progress. Airlines' network size and average stage length have a negative impact on operating cost. Thus, companies with larger networks and/or longer routes enjoy a significant cost advantage. Finally, we also introduce in the cost function our

\footnotetext{
11 Note issued by the U.S. Department of Transportation on the 20th May 1996.

12 European Commission MEMO/09/168. 20th April 2009.
} 
alliance $(A L L)$ dummy variable to test whether airlines' operating costs are reduced if airlines enter into cooperative agreements. The results suggest that alliances have no direct effect on cost since the $A L L$ effect is not significant.

Hence, it seems that alliances between airlines reduce prices significantly but they have no direct effect on costs. We expect however alliances to have a positive impact on the quantity of passengers kilometers carried (Whalen 2007), which in turn leads to a decrease of airlines' average costs due to the presence of economies of density. Thus, alliances mostly increase the flow of passengers inside the existing network, and thus reduce airlines' costs, but they do not affect airlines' cost technology.

\section{The competition effect of alliances}

We propose now to discuss further our previous findings in light of the average competitive behavior of each airline. Provided with the demand, capacity, and cost estimates, we measure the degree of competition in the industry after the introduction of alliances. We evaluate alliances' marginal costs and margins and shed light on whether the pricing behavior of airlines which are members of alliances is similar to a hypothetical Nash pricing behavior.

Provided with the cost and demand ingredients, each airline solves the following program,

$$
\max _{q_{i}} \pi_{i}=q_{i} p_{i}-C\left(Q_{i}, \omega_{i}, z_{i}\right)
$$

where $q_{i}$ is the optimal quantity to be chosen, and $Q_{i}=\Phi\left(q_{i}, \lambda\right)$. The first order condition for firm $i$, which entails Nash pricing, is given by

$$
\frac{p_{i}-\Phi^{\prime}\left(q_{i}\right) M C_{i}}{p_{i}}=-\frac{q_{i}}{p_{i}} \frac{\partial p_{i}}{\partial q_{i}},
$$

where

$$
M C_{i}=\frac{\partial C_{i}}{\partial Q_{i}} \quad \text { and } \quad \Phi^{\prime}\left(q_{i}\right)=\frac{\partial Q_{i}}{\partial q_{i}}
$$

Using the estimates of the cost, capacity and demand system obtained in the previous section, we can evaluate the price-cost margins $M_{i}=\frac{p_{i}-\Phi^{\prime}\left(q_{i}\right) M C_{i}}{p_{i}}$, and test these margins against those that could be obtained if airlines obeyed to Nash behavior, as described by the right-hand side of (1). Under Nash, firms set prices independently, since each firm $i$ only cares for its own demand $q_{i}{ }^{13}$

\footnotetext{
13 By estimating cost and demand functions, we are able to generate direct measures of the price-cost margins. This approach follows the spirit of Genesove and Mullin (1998), which shows that direct estimations of the conduct parameter through the pricing rule may lead to significant underestimation of market power. Similarly, imposing a specific conduct and estimating costs may lead to over or underestimation of costs when perfect competition or monopoly are assumed respectively. On the contrary, estimates are quite insensitive to the assumed demand functional form.
} 
Table 12 Marginal costs, prices, and margins

\begin{tabular}{|c|c|c|c|c|}
\hline & Price & $M C$ & Real Margin & Nash Margin \\
\hline \multicolumn{5}{|l|}{ Alliances } \\
\hline All carriers & $0.129(0.061)$ & $0.074(0.035)$ & $0.122(0.349)$ & $0.707(0.499)$ \\
\hline Carriers within alliances & $0.099(0.029)$ & $0.056(0.018)$ & $0.234(0.199)$ & $0.950(0.342)$ \\
\hline Carriers outside alliances & $0.132(0.063)$ & $0.076(0.036)$ & $0.108(0.360)$ & $0.677(0.507)$ \\
\hline OneWorld & $0.102(0.025)$ & $0.056(0.011)$ & $0.244(0.080)$ & $1.487(0.246)$ \\
\hline SkyTeam & $0.095(0.003)$ & $0.049(0.008)$ & $0.328(0.121)$ & $1.011(0.007)$ \\
\hline Qualiflyer & $0.095(0.016)$ & $0.067(0.013)$ & $0.022(0.266)$ & $0.751(0.211)$ \\
\hline Star Alliance & $0.101(0.035)$ & $0.053(0.021)$ & $0.308(0.103)$ & $0.930(0.317)$ \\
\hline Wings & $0.148(0.061)$ & $0.087(0.041)$ & $0.192(0.175)$ & $0.959(0.587)$ \\
\hline \multicolumn{5}{|l|}{ Substitute airlines } \\
\hline \multicolumn{5}{|l|}{ One } \\
\hline American Airlines & 0.082 & 0.046 & 0.258 & 2.695 \\
\hline British Airways & 0.101 & 0.050 & 0.361 & 1.456 \\
\hline Qantas & 0.072 & 0.044 & 0.224 & 1.683 \\
\hline Cathay & 0.068 & 0.028 & 0.451 & 1.984 \\
\hline Canadian Airlines & 0.057 & 0.037 & 0.132 & 2.109 \\
\hline \multicolumn{5}{|l|}{ Star Alliance } \\
\hline United Airlines & 0.076 & 0.045 & 0.246 & 3.332 \\
\hline Lufthansa & 0.111 & 0.045 & 0.487 & 0.810 \\
\hline Mexicana & 0.092 & 0.052 & 0.190 & 0.711 \\
\hline All Nippon Airways & 0.133 & 0.070 & 0.248 & 1.270 \\
\hline SAS & 0.175 & 0.095 & 0.227 & 0.603 \\
\hline Thai Airways & 0.061 & 0.033 & 0.294 & 1.043 \\
\hline
\end{tabular}

Price: One passenger-kilometer in Dollars. $M C$ : One seat-kilometer in Dollars. Standard errors are in parenthesis

From the expressions of demand (5), capacity (8) and costs (6), the price first-order condition under Nash behavior can be rewritten as

$$
\frac{p_{i}-\frac{\lambda_{1} Q_{i}}{q_{i}} M C_{i}}{p_{i}}=-\frac{q_{i}}{p_{i}} \frac{1}{\alpha_{1}} .
$$

Through the estimation of the cost function, the marginal costs $M C_{i}$ can be easily recovered since $M C_{i}=\beta_{3} \frac{C_{i}}{Q_{i}}$. Putting them together with our estimate of the capacity-demand elasticity $\lambda_{1}$, as well as the observed values for supply, demand and prices, we are able to evaluate the price-marginal cost margin $M_{i}$ set by each airline. We refer to $M_{i}$ as the actual margin since it directly depends on the observation of $p_{i}, q_{i}, Q_{i}$, $C_{i}$ and the parameters $\lambda_{1}$ and $\beta_{3}$.

Table 12 presents the estimated values for marginal costs $M C_{i}$, and margins $M_{i}$, for all firms and alliances. Several results are worth emphasizing. 
First, the average airline enjoys a positive margin. Second, distinguishing companies belonging to alliances from companies outside alliances, it seems that companies within alliances obtain higher margins. However, these companies set lower prices and face lower marginal costs. Note that this latter result (lower marginal costs) is not inconsistent with the non-significant alliance effect on costs which is presented in Table 11. Indeed, the alliance effect in Table 11 is in principle independent of any airline characteristics, while the average marginal cost for alliance members computed in Table 12 is conditional on airline characteristics. As discussed in the previous section, alliance members may enjoy lower marginal costs because alliances are potentially clubs which gather more efficient and/or larger companies, compared to those outside alliances.

Third, note that prices, marginal costs, and margins vary significantly across alliances. A striking result is the average margin of Qualiflyer which is close to 0 . This could be related to the negative profit obtained by some of its airlines for several years, illustrating the financial difficulties of the alliance, which stopped its operations in 2001 after the bankruptcies of Swissair and Sabena.

Using our estimates for the demand equation, note that, as suggested by the righthand side of Equation (11), Nash behavior would entail an average margin $M_{N}^{T}$ for all the airlines in the sample equal to 0.707 . On average, the industry's actual margin $M^{T}=0.122$ does not entail pure Nash behavior. It is also worth distinguishing airlines that belong to alliances and those that do not. We have suggested that companies within alliances were setting the highest margins. We also calculate an average individual Nash margin for each group. Note that, from the ratio $q_{i} / p_{i}$, evaluated at the average observation of the sample, it can be seen that the airlines within alliances meet demand on a more inelastic portion of the curve than other companies. Hence, pure Nash behavior for companies inside alliances entails a margin $M_{N}^{A}$ equal to 0.950 , while for other companies the margin, $M_{N}^{N A}$, is equal to 0.677 . The values of these actual margins lie below the individual Nash behavior margins. Hence, individual Nash behavior is not met for any set of companies. We can as well evaluate an average Nash margin for each alliance. Airlines inside these alliances show a behavior that is different from individual Nash. According to our results, Airlines in SkyTeam and Star Alliance are those characterized by the less competitive behavior.

Note that Star Alliance (OneWorld resp.) includes six (five resp.) airlines whose networks are substitutes to other airlines' networks inside the same alliance. We present in the lower half of the table individual estimates for these companies, which are American Airlines, British Airways, Qantas, Cathay, Canadian Airlines, United, Lufthansa, All Nippon, SAS, Thai, and Mexicana. Note that, compared to the average airline inside an alliance, a majority of them enjoy higher margins, since they benefit from marginal costs advantages and/or they set higher prices. Comparing the real margins to individual Nash margins suggests that Lufthansa, Mexicana, SAS, and Thai have the less competitive behavior.

\section{Conclusion}

After worldwide liberalization of the airline market, competition has led firms to start forming alliances. Economic studies have proposed that alliances between air- 
lines whose networks can be regarded as substitutes should result in softer competition and higher prices. At the same time, alliances between firms whose networks can be regarded as complements should result in lower prices due to cost reductions. The former type of alliance should be avoided, but the latter should be promoted.

This study sheds light on these issues. Our contribution consists in evaluating airlines' strategical interactions through the window of firms' network interconnections. To estimate cross-price elasticities for all the networks of our database, we consider airlines' networks coincidences and potential connections with all their rivals. The results allow us to classify all company pairs as either complements or substitutes, and predict price cost margins.

Our results suggest that a significant number of companies that are allied between 1995 and 2000 can cooperate on routes that were jointly served before, so that many members' networks can be considered as substitutes.

At the same time, we show that, on average, alliance members propose lower prices than airlines outside alliances. We suggest that this negative impact of alliances on prices does not correspond necessarily to a change in airlines' pricing once they are part of an alliance. We rather believe that alliances are clubs of large and efficient companies, in which the members are able to set lower prices because they enjoy lower costs.

Open Access This article is distributed under the terms of the Creative Commons Attribution Noncommercial License which permits any noncommercial use, distribution, and reproduction in any medium, provided the original author(s) and source are credited.

\section{References}

Bamberger GE, Carlton DW, Neumann LR (2004) An empirical investigation of the competitive effects of domestic airline alliances. J Law Econ 47:195-222

Berechman J (1993) Public transit economics and deregulation policy. North Holland, Amsterdam

Borenstein S (1989) Hubs and high fares: dominance and market power in the U.S. airline industry. Rand J Econ 20:344-365

Brueckner JK (2001) The economics of international codesharing: an analysis of airline alliances. Int J Ind Organ 19:1475-1498

Brueckner JK (2003) International airfares in the age of alliances: the effects of codesharing and antitrust immunity. Rev Econ Stat 85:105-118

Brueckner JK, Whalen T (2000) The price effects of international airline alliances. J Law Econ 43:503-545

Gagnepain P, Marin PL (2006) Regulation and incentives in European aviation. J Law Econ 49:229-248

Genesove D, Mullin WP (1998) Testing static oligopoly models: conduct and cost in the sugar industry, 1890-1914. RAND J Econ 29:355-377

Good DH, Röller L-H, Sickles RC (1993) US airline deregulation: implications for European transport. Econ J 103:1028-1041

Jaumandreu J, Lorences J (2002) Modelling price competition across many markets (an application to the spanish loans market). Eur Econ Rev 46:93-115

Marín PL (1998) Productivity differences in the airline industry: partial deregulation versus short run protection. Int J Ind Organ 16:395-414

Neven DJ, Röller L-H (1996) Rent sharing in the European airline industry. Eur Econ Rev 40:933-940

Neven DJ, Röller L-H, Zhang Z (2006) Endogenous costs and price-cost margins. J Ind Econ 54:351-368

Oster SM (1994) Modern competitive analysis, 2nd edn. Oxford University Press, New York

Oum TH, Park JH (1997) Airline alliances: current status, policy issues, and future directions. J Air Transp Manage 3:133-144 
Oum TH, Park J, Zhang A (1996) The effects of airline codesharing agreements on firm conduct and international airfares. J Transp Econ Policy 30:187-202

Oum TH, Waters II WG, Yong JS (1992) Concepts of price elasticities of transport demand and recent empirical estimates. J Transp Econ Policy 26:139-154

Röller L-H, Sickles RC (2000) Capacity and product market competition: measuring market power in a puppy-dog' industry. Int J Ind Organ 18:845-865

Whalen WT (2007) A panel data analysis of code-sharing, antitrust immunity, and open skies treaties in international aviation markets. Rev Ind Organ 30:39-61 